\title{
Systemic absorption of noxythiolin from the pleural cavity in man and in the rabbit
}

\author{
F L ROSENFELDT, J R GLOVER, AND D MAROSSY
}

From The Rayne Institute and the Department of Cardiothoracic Surgery, St Thomas' Hospital, London

ABSTRACT Systemic side-effects during irrigation of body cavities with the antiseptic noxythiolin (Noxyflex) have not previously been reported. In two patients undergoing intrapleural lavage with $1 \%$ iv noxythiolin, anorexia and nausea with or without vomiting were observed which suggested systemic ${ }^{\infty}$

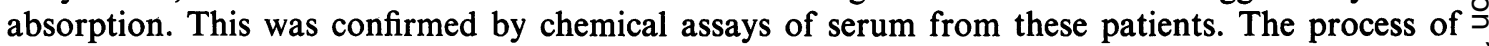
absorption was studied in rabbits by injection of noxythiolin into the pleural or peritoneal cavity. $\vec{\nabla}$ Serum levels reached a peak at one to two hours indicating rapid entry into the bloodstream, declined slowly over seven hours, and reached zero before 24 hours. Although side-effects resulted from systemic $\vec{\bullet}$ absorption of noxythiolin during irrigation of the pleural cavity, they were mild and did not contra- $\stackrel{\infty}{-}$ indicate the use of noxythiolin as an irrigant. Awareness of the mechanism of side-effects of noxythiolin provides a rational basis for management of symptoms through reduction of the volume or frequency of irrigation.

The widespread use of antibiotics in recent years has resulted in a rising incidence of antibiotic resistance in bacteria. ${ }^{1}$ As a result there is an increasing role for antiseptics in treating infections in body cavities or on the skin. The instillation of antibacterial drugs into the pleural cavity is an accepted and effective form of therapy for intrapleural infection especially after pneumonectomy. Clagett recommended intrapleural neomycin in his procedure for the management of post-pneumonectomy empyema because of its broad anti-bacterial spectrum. ${ }^{2}$ However Meakins and Allard recently reported neomycin toxicity following Clagett's procedure. They urged caution in the intrapleural use of neomycin and advised routine monitoring of serum levels. ${ }^{3}$

Noxythiolin (Noxyflex) is an antiseptic of low toxicity which is frequently instilled into the bladder or peritoneal cavity. ${ }^{5}$ Systemic side-effects have not previously been reported. In the preceding article $^{6}$ we report the use of intrapleural noxythiolin in three patients to control infection. In two of these patients we observed anorexia, nausea, and vomiting as possible side-effects. This suggested systemic absorption of noxythiolin from the pleural cavity. An assay was therefore used to monitor serum levels of noxythiolin in patients in whom side-effects were observed. In a study in rabbits, the absorption of noxythiolin from the pleural cavity was measured and

Address for reprint requests: FL Rosenfeldt, Baker Medical Research Institute, Commercial Road, Prahran, 3181 Victoria, Australia. a search made for cardiovascular side-effects during $\stackrel{\mathbb{2}}{\Rightarrow}$ intravenous infusion of noxythiolin.

\section{Methods}

PATIENT DOSING AND SAMPLING

Serum samples were obtained from four patients receiving local noxy thiolin therapy: two for empyema, $\stackrel{\times}{\circ}$ one for septic pericarditis, and one for osteomyelitis. The patients' characteristics and the dosages used are detailed in the table. In two patients, samples were $\frac{3}{3}$ obtained during the occurrence of side-effects of noxythiolin.

\section{RABBIT STUDIES}

Absorption

New Zealand white rabbits were injected with $1 \%$ noxythiolin in normal saline. There were two methods of injection. Intrapleural: in this method noxythiolin ${ }_{\sigma}^{\omega}$ was injected as a bolus into one pleural cavity. The rabbits were divided into three dosage groups: group 1 included four rabbits given $57 \mathrm{mg} / \mathrm{kg}$; group 2 consisted of eight rabbits given $28.5 \mathrm{mg} / \mathrm{kg} ;$ group 3 contained two rabbits given $14.25 \mathrm{mg} / \mathrm{kg}$. The dosage in group 1 was midway between the dosages used 12-hourly in the two patients experi- $\frac{?}{\mathbb{D}}$ encing side-effects. Samples of venous blood were taken before and at approximately hourly intervals? for up to seven hours after the instillation of noxy-尺 thiolin. In four animals, samples were also taken ato 
Table Serum levels of noxythiolin in patients

\begin{tabular}{|c|c|c|c|c|c|c|}
\hline Patient & $\operatorname{Sex}$ & $\operatorname{Age}(y r)$ & Diagnosis & $\begin{array}{l}\text { Route of administration } \\
\text { and dose }\end{array}$ & $\begin{array}{l}\text { Serum level } \\
(\mu \mathrm{g} / \mathrm{ml})\end{array}$ & Side-effects \\
\hline 1 & $\mathbf{F}$ & 69 & Empyema & $\begin{array}{l}\text { Intrapleural }{ }^{*} \\
2 \cdot 5 \mathrm{~g}(42 \mathrm{mg} / \mathrm{kg}) \\
12 \text { hourly for nine days }\end{array}$ & 48 & $\begin{array}{l}\text { Malaise, } \\
\text { anorexia, } \\
\text { nausea, } \\
\text { vomiting }\end{array}$ \\
\hline 2 & $\mathbf{F}$ & 80 & Empyema & $\begin{array}{l}\text { Intrapleural* } \\
2 \mathrm{~g}(25 \mathrm{mg} / \mathrm{kg}) \\
4 \text { hourly for five days }\end{array}$ & 62 & $\begin{array}{l}\text { Malaise, } \\
\text { anorexia, } \\
\text { nausea }\end{array}$ \\
\hline 3 & $\mathbf{M}$ & 45 & $\begin{array}{l}\text { Septic } \\
\text { pericarditis }\end{array}$ & $\begin{array}{l}\text { Intrapericardial } \\
\text { Continuous drip of } 1 \% \\
\text { solution }\end{array}$ & 11 & Nil \\
\hline 4 & $\mathbf{M}$ & 44 & Osteomyelitis & $\begin{array}{l}\text { Intraosseous } \\
\text { Continuous drip of } 1 \% \\
\text { solution }\end{array}$ & 8 & Nil \\
\hline
\end{tabular}

*The pleural cavity was filled with $1 \%$ noxythiolin for three hours and allowed to drain.

24 hours. Two months later the rabbits were killed and the pleural cavities examined. Intraperitoneal: in this method two rabbits were given intraperitoneal noxythiolin $28.5 \mathrm{mg} / \mathrm{kg}$. Hourly blood samples were taken for four hours. Two months later these rabbits were killed and the peritoneal cavities examined.

\section{Cardiovascular effects}

In two rabbits anaesthetised with urethane $(1 \cdot 25 \mathrm{~g} / \mathrm{kg})$, arterial blood pressure, heart rate, and respiratory rate were recorded while $1 \%$ noxythiolin in normal saline was given as an intravenous infusion at a rate of $1 \mathrm{mg} / \mathrm{kg}$ per minute.

\section{Noxythiolin assay}

An assay for organic sulphur compounds such as the thioureas was originally described by Grote. ${ }^{7}$ Grote's specific reagent can be used with slight modification for the assay of noxythiolin. The assay does not distinguish between noxythiolin and its breakdown product methylthiourea. We have scaled down the assay for use with $1 \mathrm{ml}$ samples of serum.

To $1 \mathrm{ml}$ of serum, $0.5 \mathrm{ml}$ of sodium tungstate solution $(10 \%$ anhydrous by weight) and $0.5 \mathrm{ml}$ of 0.5 molar $\mathrm{H}_{2} \mathrm{SO}_{4}$ were added, and the mixture was centrifuged. To $0.6 \mathrm{ml}$ of the supernatant, $0.4 \mathrm{ml}$ of $14 \%$ fresh $\mathrm{Na}_{2} \mathrm{HPO}_{4} .2 \mathrm{H}_{2} \mathrm{O}$ and $0.1 \mathrm{ml}$ of diluted Grote's reagent ( 1 in 5) were added. The OD $_{610 \mathrm{~nm}}$ was measured after one hour. A simultaneous standard was prepared using noxythiolin dissolved in serum and the serum levels calculated from the standard curve. Grote's reagent was made by dissolving $0.5 \mathrm{~g}$ sodium nitroprusside in $10 \mathrm{ml}$ water, and adding $0.5 \mathrm{~g}$ hydroxylamine hydrochloride and $1 \mathrm{~g} \mathrm{NaHCO}_{3}$ mixed together. When the evolution of gas had ceased, $0.1 \mathrm{ml}$ bromine was added, the mixture diluted to $25 \mathrm{ml}$ with water, and allowed to stand at room temperature for five to 10 hours before being stored at $4^{\circ} \mathrm{C}$. This solution was diluted 1 in 5 for assay. The assay was sensitive enough to detect concentrations of noxythiolin as low as $5 \mu \mathrm{g} / \mathrm{ml}$.

A partitioning test in whole blood showed that noxythiolin was equally distributed between red cells and serum. No evidence of binding to plasma protein was found.

\section{Results}

\section{PATIENTS' RESPONSES AND ASSAY RESULTS}

Patient 1 received $42 \mathrm{mg} / \mathrm{kg}$ of noxythiolin 12-hourly intrapleurally and a serum level of $48 \mu \mathrm{g} / \mathrm{ml}$ was reached. She complained of malaise, anorexia, nausea, and vomiting. Irrigation was stopped for 24 hours in the middle of the course of treatment. The nausea and vomiting disappeared during this period only to reappear when irrigation was started. She felt well again when the nine-day course of irrigation was completed. Her empyema was sterilised and she suffered no permanent ill effects from the therapy.

Patient 2 received $25 \mathrm{mg} / \mathrm{kg}$ of intrapleural noxythiolin four hourly and her serum level reached $62 \mu \mathrm{g} / \mathrm{ml}$. She complained of malaise, anorexia, and nausea during the five-day period of irrigation with noxythiolin. These symptoms disappeared when the course of irrigation was completed.

The other two patients who received a continuous infusion of $1 \%$ noxythiolin into the pericardial cavity or into the site of an infected fractured femur had serum levels of $11 \mu \mathrm{g} / \mathrm{ml}$ and $8 \mu \mathrm{g} / \mathrm{ml}$ respectively. Neither of these patients showed any side-effects. These results are summarised in the table.

\section{RABBIT STUDIES}

\section{Absorption}

Figure 1 shows examples of the rise and fall of serum levels after the injection of $28.5 \mathrm{mg} / \mathrm{kg}$ of noxythiolin into the pleural cavity in three rabbits and into the peritoneal cavity in two rabbits. Serum concentration 
reached a peak in one to two hours and declined in a linear fashion over the seven-hour sampling period.

Figure 2 shows the mean curves for the three dosage groups of intrapleural noxythiolin. Rapid absorption was seen at all dose levels. Peak serum levels occurred at three to four hours in group 1 and at one to two hours in groups 2 and 3. In four rabbits in group 2, serum samples were obtained at 24 hours. These showed no detectable noxythiolin.

None of the rabbits showed any abnormality in the pleural or peritoneal cavities at necropsy. In particular there was no inflammation, adhesion formation, or scarring.

\section{Cardiovascular effects}

Intravenous infusion of noxythiolin in two rabbits produced no change in arterial pressure, heart rate, or respiratory rate. In one rabbit a serum noxythiolin level of $50 \mu \mathrm{g} / \mathrm{ml}$ was reached and in the other $600 \mu \mathrm{g} / \mathrm{ml}$.

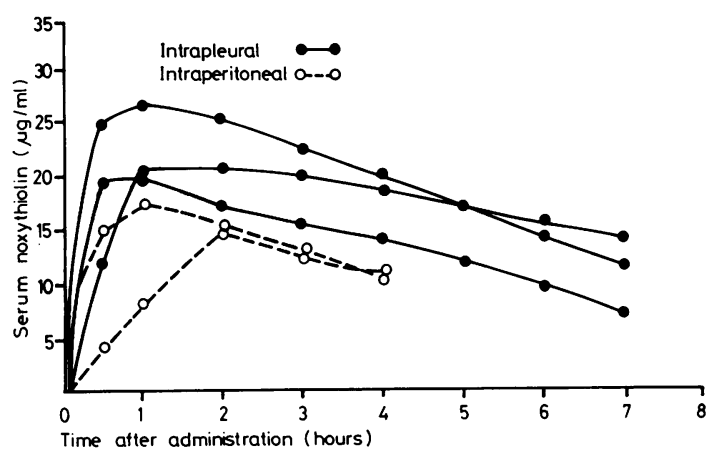

Fig 1 Serum levels of noxythiolin after an intrapleural or intraperitoneal injection of $28.5 \mathrm{mg} / \mathrm{kg}$ in five rabbits.

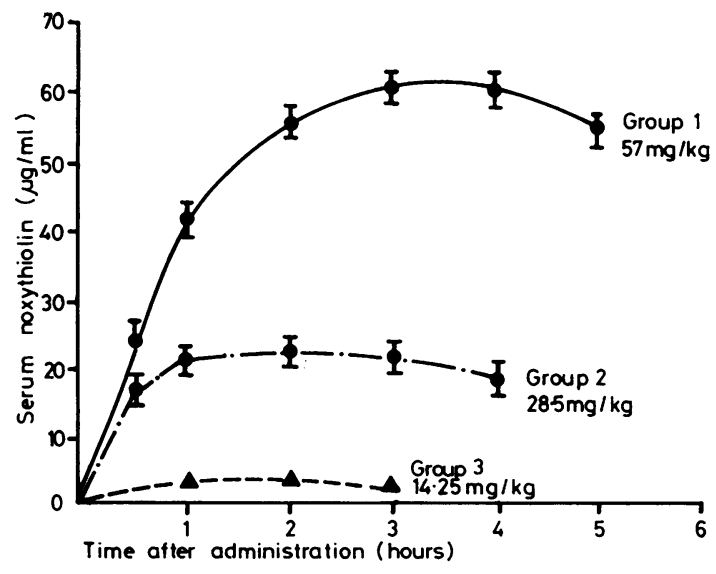

Fig 2 Serum noxythiolin concentrations (mean $\pm S E M$ ) after intrapleural administration in three groups of rabbits.

\section{Discussion}

Two patients with anorexia and nausea during treatment of empyema by irrigation had high serum levels of noxythiolin. The dose used at each instillation $(2-2.5 \mathrm{~g})$ was similar to that recommended for intraperitoneal use. ${ }^{5}$ The relation of the malaise, anorexia, and nausea to the timing of the irrigations in these two patients was striking. The side-effects also coincided with high serum levels of noxythiolin. Two patients who had noxythiolin irrigation of small body cavities had low serum levels and no side-effects. It seems reasonable therefore to conclude that systemic absorption of noxythiolin can cause malaise, anorexia, nausea, and vomiting. Why has this effect not been reported before? Several explanations are possible. First, in regions of the body where repeated noxythiolin irrigation is used, the surface lining has either a small area for absorption, as in a wound sinus, or does not absorb aqueous solutions, as in the bladder. Second, in the peritoneal cavity which has an absorptive lining, noxythiolin is most often used as a single instillation and therefore the opportunity for accumulation in the serum does not occur. In a report by Pickard of the use of repeated instillations of noxythiolin into the peritoneal cavity, ${ }^{8}$ the patients were probably so ill from peritonitis that the relatively mild effects of noxythiolin absorption were overlooked.

In the present study the side-effects observed were mild and disappeared on discontinuation of the therapy. Infusing noxythiolin intravenously into anaesthetised rabbits caused no significant cardiac or respiratory effects even when serum levels were 10 times higher than those observed in the affected patients. This suggested a wide margin of safety between therapeutic dose and serious toxicity. The lethal dose in mice for intraperitoneal noxythiolin is $1650 \mathrm{mg} / \mathrm{kg}$ (data supplied by Geistlich Sons Ltd, Chester) which is 40 times the highest individual dose we have used clinically.

The possibility exists that the anorexia, nausea, and $\tilde{N}$ vomiting observed during noxythiolin therapy were $N$ caused by the systemic absorption of the amethocaine $N$ which is added to noxythiolin (Noxyflex) to prevent $\omega$ painful irritation by the solution. However this is unlikely because the nausea and vomiting of ametho- $\stackrel{0}{\mathcal{C}}$ caine toxicity are usually seen as part of a generalised excitation of the central nervous system manifested by excitement, restlessness, dizziness, muscle twitching, and convulsions. Such effects were never observed in patients receiving noxythiolin.

In the rabbit, noxythiolin was rapidly absorbed $\stackrel{\mathbb{2}}{\circ}$ from the pleural cavity and reached a peak concentration in one to three hours. We estimate that the 8 serum level fell to half its peak level between six and 
10 hours. There was no detectable noxythiolin at 24 hours. These times cannot be interpreted as measures of the serum half-life of noxythiolin because of continuing absorption from the pleural space and also because the assay does not distinguish between noxythiolin and its breakdown product methylthiourea. However they serve as a guide to the duration of side-effects of intrapleural noxythiolin. Louis and Benedetti measured blood radioactivity in the rat after the intraperitoneal administration of labelled noxythiolin and showed rapid absorption and peak activity at 30 to 60 minutes. ${ }^{9}$ As in the present study it was not possible to distinguish between noxythiolin and its breakdown products in the serum. The results of our limited studies of the intraperitoneal absorption of noxythiolin were similar to the intrapleural studies.

As would be expected there was a relationship between the peak serum level of noxythiolin and the volume of $1 \%$ noxythiolin introduced into the pleural cavity. The dosage in group $1,57 \mathrm{mg} / \mathrm{kg}$, was nearest to the clinical regimen and produced the same peak serum level as that measured in patient 2 , who had side-effects. Halving the dosage (group 2) led to a three-fold reduction in peak serum levels.

How should these results influence the practical management of intrapleural irrigation with noxythiolin or other potentially toxic substances? Great reductions in the volume of irrigant solution are undesirable because much of the beneficial effect of irrigation is caused by the physical action of the fluid in washing out infected material. Reducing the concentration of noxythiolin below $1 \%$ is also undesirable as this impairs its antibacterial effect. One solution to the problem which we have used is to begin with four-hourly irrigations of $100-200 \mathrm{ml}$ of $1 \%$ noxythiolin and after $12-24$ hours to alternate these with one or more four-hourly cycles of normal saline.

We conclude that while side-effects can result from systemic absorption of noxythiolin during irrigation of the pleural or peritoneal cavities, systemic absorption is not dangerous and routine monitoring of serum levels is not essential. Systemic absorption can be detected clinically and if necessary the volume or frequency of irrigation reduced.

We wish to express our thanks for advice and assistance to Dr David Hearse of the Myocardial Metabolism Research Laboratory, Mr MV Braimbridge of the Department of Cardiothoracic Surgery, Dr S Eykyn of the Department of Microbiology, and Professor Bissett of the Department of Pharmacology of St Thomas' Hospital.

\section{References}

1 Balows, A. An overview of recent experiences with plasmid-mediated antibiotic resistance or induced virulence in bacterial diseases. J Antimicrob Chemother 1977; 3 (suppl C): 3-6.

2 Clagett OT, Geraci JE. A procedure for the management of postpneumonectomy empyema. $J$ Thorac Cardiovasc Surg 1963; 45: 141-5.

3 Meakins JL, Allard J. Neomycin absorption following Clagett procedure for postpneumonectomy empyema. Ann Thorac Surg 1980; 29: 32-5.

4 McFadyen IR. Comparison of noxythiolin (Noxyflex) and chlorhexidine (Hibitane) instillations after intermittent catheterization. Clinical Trials Journal (London) 1967; 4: 654-7.

5 Brown MK, Stoller JL. Intraperitoneal noxythiolin in faecal peritonitis. Br J Surg 1970; 57: 525-9.

6 Rosenfeldt FL, McGibney D, Braimbridge MV, Watson DA. Comparison between irrigation and conventional treatment for empyema and pneumonectomy space infection. Thorax $1981 ; 36: 272-7$.

7 Grote IW. A new color reaction for soluble organic sulfur compounds. J Biol Chem 1931; 93: 25-30.

8 Pickard RG. Treatment of peritonitis with per- and post-operative irrigation of the peritoneal cavity with noxythiolin solution. Br J Surg 1972; 59: 642-8.

9 Louis A, Benedetti MS. Absorption, elimination, metabolic fingerprint of ${ }^{14} \mathrm{C}$-labelled noxythiolin in the rat. Report. Geistlich Sons Ltd, Chester, England. 